\title{
The Open Studio: Exploring Immigrant and Refugee Youth Experiences of Belonging through Community-Based Arts Practice
}

\author{
Leah B. Lewis, Memorial University of Newfoundland \\ leah.lewis@mun.ca \\ Heather McLeod \\ Memorial University of Newfoundland \\ Xuemei Li \\ Memorial University of Newfoundland
}

\begin{abstract}
The Open Studio is a publicly accessible art-making space grounded in ideals of collaborative community development, Adlerian theory, social justice, and feminist thoughts. Our project involved visual art-making and exploring high school immigrant students' experiences of inclusion and belonging. The purpose was to help immigrant and refugee youth to adapt to a city in Newfoundland, where newcomers often face an insider/outsider dynamic of disconnection. The Open Studio was structured along seven parameters: focus on intentional art-making; no judgmental commentary (positive or negative); non-evaluative in nature; no forced participation, including witnessing and sharing; and as importantly, participatory involvement of facilitators. The participant-planned and hosted final school exhibit contributed to learning, sharing, and group cohesiveness. A plain language needs assessment, semi-structured interviews, and focus group, were also used to generate data on how an Open Studio informs cultural experiences and feelings of integration and belonging.
\end{abstract}

Keywords: Immigrant and refugee youth, art-making, belonging, integration

Canada is a diverse country demographically with $20 \%$ of the national population identifying as falling within the federal government's classification, 'visible minority'. The majority of whom reside in the larger urban centres (Statistics Canada, 2012). The Newfoundland and Labrador (NL) settler context is historically homogeneous with the representation of visible minority groups rising to around $2 \%$ in the 2011 and 2016 censuses (Statistics Canada, 2012; 2016). The majority of the ethnic minorities reside in the St. John's metropolitan area, as shown in the language spoken at home. In $2011,97.1 \%$ of the population in the St. John's metropolitan area spoke English most often at home, and 2.0\% spoke only a nonofficial language (98.5\% for only English and 1.0\% for only a non-official language provincewide) (Statistics Canada, 2016). This demographic differs greatly from other metro regions in Canada. It contrasts with $46 \%$ of Toronto residents, $20 \%$ of the metro Montreal area, and $45 \%$ of metro Vancouver who identify as immigrants (Statistics Canada, 2011). Adjustment processes for immigrant families in small, less populated areas, like NL, appear different than in larger Canadian urban centres (Li, Doyle, Lymburner, \& Ghadi, 2016). 
It was in this context and based on findings of existing studies (Baker, Price, \& Walsh, 2015; Burnaby, 2010; Doyle, Li, \& Grineva, 2016; Li, Doyle, Lymburner, \& Ghadi, 2016; Li \& Grineva, 2016; Li \& Que, 2015), that we designed and administered this project to engage immigrant and refugee students and to empower them through art-making. We collaborated with a local high school, currently hosting the largest group of immigrant and refugee students in St. John's, Newfoundland. Working from a community collaborative perspective, using an artsbased process (Leavy, 2009), our project explored the social and cultural integration of immigrant youth in the city. We used Heron and Reason's (1997) theory of extended epistemology, in which experiential methods of inquiry are grounded in cooperative and interpersonal relationships. The project was called Open Studio (OS), with the aim of helping immigrant and refugee youth cope with integration. The project ran weekly for 16 weeks from December, 2016 to April, 2017 in which immigrant and refugee students actively participated, in an after-school group process.

\section{Newcomer Youth Challenges}

Immigrants and refugees from non-traditional countries constitute the majority of newcomers to Canada. In this article, we use newcomer as an umbrella term, but our focus is on immigrants and refugees arriving through official channels. Although in years past Canada received primarily European immigrants, in recent decades the majority of immigrants to Canada are visible minorities (Reitz, 2005). Newfoundland and Labrador has experienced a similar demographic shift. For example, the most-spoken non-official languages in the St. John's metropolitan area were Chinese, German, Arabic, Tagalog (Filipino) in 2011. In 2012-13, the top three source countries for the 101 refugees to the province were Bhutan and/or Nepal, Democratic Republic of Congo, and Ethiopia (Association for New Canadians, 2013). In 2014, the majority of the 317 provincially-sponsored economic immigrants hailed from the Philippines, China, and India (Provincial Nominee Program Fact Sheet, 2014). Statistics Canada recorded 320,000 newcomers arriving in Canada in 2016, including over 30,000 Syrian refugees, and NL was among the six provinces that saw a record number of immigration (Grant, 2016). During July 1, 2015-June 30, 2016, the province received 1,406 immigrants (Statistics Canada, 2016c), of which roughly 260 were Syrian refugees (ANC, 2016), reflecting a high ratio of $18.5 \%$ refugees among newcomers to NL.

In demographic terms, Newfoundland and Labrador remain very homogeneous with less than $2 \%$ of the population self-identifying as a visible minority as compared to almost $20 \%$ nationally (Statistics Canada, 2012). In a province known for its strong sense of a local culture, community, and sense of place, newcomers may experience a tangible and potentially difficult insider/outsider dynamic (Anderson, 2012; Lepawsky, Phan, \& Greenwood, 2010). For example, Locke and Lynch (2005) pointed out that local employers had a negative attitude toward hiring newcomers, and less than $10 \%$ of them had hired a newcomer in the five years prior to the study. Anderson (2012) found, in some parts of rural Newfoundland, that intimate interaction between "local" people and new arrivals in particular can be rare, and further that many newcomers feel socially isolated. Incidents of not feeling accepted also exist in the capital city (Baker, Price, \& Walsh, 2015; Li \& Grineva, 2016), and were expressed by the participants in this project.

The majority of the newcomers to NL reside in the St. John's metropolitan area. While the total population of NL increased by 5,180 people from 2011 to 2016, the increase in St.

Cultural and Pedagogical Inquiry, Summer 2018, 10(1), pp. 5-21

ISSN 1916-3460 (C) 2018 University of Alberta

http://ejournals.library.ualberta.ca/index.php/cpi/index 
John's during the same period was 9,001 people (Statistics Canada, 2016b). Apart from the trend of immigrants moving away from big centres and into smaller centres, such as St. John's, the increase of government sponsored refugees in recent years also contributed to population growth. During 2015-2016, the Association for New Canadians served 327 new Government Assisted Refugees from eight countries, including Syria, Eritrea, Congo, and Iraq (ANC, 2016). All the high school age refugees were placed in one particular high school in St. John's with English-asa-second-language and academic bridging programs.

Exploring how young immigrants and refugees experience a sense of belonging is important. Studies conducted with refugee youth in St. John's, for example, revealed that racism was having a negative effect on their lives and contributed to feelings of being unwelcome (Baker, 2013). Indeed, nearly $40 \%$ of visible minority high school students said that they had experienced racism from their peers (Baker, Price, \& Walsh, 2015).

Although programs have been established in a limited number of schools to help alleviate the stress levels of newcomer youth, some problems remain, such as a lack of counselling services to address issues of developing social connections and a sense of belonging ( $\mathrm{Li} \&$ Que, 2016), as well as, addressing difficulties in communication and interaction (Li \& Grineva, 2016). Since language was identified as a significant barrier to integration in current Newfoundlandbased research on immigrant refugee youth (Burnaby, 2010; Sarma-Debnath \& Castano, 2008), we chose to use visual art in the Open Studio research project.

\section{Open Studio Project}

Open Studio (OS) is a form of community-based arts practice (CBA). It is a publicly accessible space intended for group and individual gatherings for the purpose of engagement through art-making. The CBA/OS process originates from community-based art therapy practice and is grounded in the ideals of collaborative community development and Adlerian theory (Adler, 1932), with current CBA/OS practice being additionally informed by social justice and feminist models (Timm-Bottos \& Reilly, 2015). OS uses the art-making process as a community building strategy that is both inclusive and accessible (Timm-Bottos \& Reilley, 2015). Artmaking is primarily a process-oriented activity, not reliant on common language, and is inherently both social and developmental (Moon, 2009), emphasizing the act of art-making as socially engaging over traditional and critical focus on taught technique. Bridging the gap between art therapy practitioners and community, the OS movement seeks to bring the art studio into communities for the sake of facilitating access and igniting community engagement, from both a social action and therapeutic perspective (Timm-Bottos \& Reilly, 2014).

Our project was inspired by the growing prevalence of community-based studios within both community and university settings across Canada. Partly in response to a nation-wide call for universities to work collaboratively with community groups, OS has surfaced as a modality for partnership between marginalized neighbourhoods and university institutions (Eleniak, Cannings, Demill, \& Samra, 2016; Timm-Bottos \& Reilley, 2015). A central aim of these community-based initiatives includes the acknowledgement that learning and change takes place in multiple contexts. La Ruche D'Art, an OS 'storefront classroom', is one of multiple Montrealbased community studios networked with Concordia University’s Masters in the Art Therapy program. Graduate students in Creative Arts Therapies complete community-based internships that seek to engage and empower a community by adopting a collaborative participatory

Cultural and Pedagogical Inquiry, Summer 2018, 10(1), pp. 5-21

ISSN 1916-3460 (C) 2018 University of Alberta

http://ejournals.library.ualberta.ca/index.php/cpi/index 
framework (Timm-Bottos \& Reilley, 2015). Of particular focus is the use of an alternative lens of learning through active participation in a 'third space' (Timm-Bottos \& Reilly, 2014) in community contexts that foster engagement and offer applied learning spaces outside of traditional seminar-learning environments (Block, Harris, \& Laing, 2005).

CBA/OS is known to inform multiple fields of learning that can help address economic, social and educational development. Initiatives focus on youth participation and acknowledge multidimensional learning needs necessary for holistic development (Timm-Bottos \& Reilley, 2015; 2014). Newman and colleagues promote benefits of CBA/OS in social, communal, personal, economic and educational development (2003). CBA/OS bring together many stakeholders in familiar community locations that are easy to access, such as schools, community centres, church basements, inner-city locations, etc. The social implications of engaging through publicly accessible and inviting spaces speak to increases in confidence, resulting from new skill development and improved social cohesion by fostering friendships and exchange with multiple and diverse levels of experience and identity. Increased senses of identity and inclusion among marginalized youth contribute to their improvements in academic performance and other forms of proactive community engagement, such as part-time jobs or team sports and volunteerism. Group contexts are also known to foster interpersonal exchange, including in this case language acquisition resulting from ongoing and repeated social interaction (Newman, Curtis, \& Stephens, 2003; Yalom, 2005).

CBA/OS is a model of group programing grounded in Adlerian thought, defined by themes of belonging, valued contribution, and altruism as essential building blocks to mental health and development of a cohesive community (Eleniak et al., 2016). Adler promoted the idea that valued experiences create value and confidence of self (1932). The need to achieve a grounded sense of belonging is central to overall mental health and functioning. Bettner and Lew (1990) summarize the achievement of this need via Adler's framework of the Crucial 'Cs'; feeling connected with others, feeling competent in our skills and ability to take responsibility, feeling that we count or are valued and, lastly, feeling able to cope with challenging or stressful experience, by possessing courage. These building blocks can be achieved via multiple experiences and contexts, and contribute to healthy personality development and functioning. For example, in his study of Canadian immigrants, Pearce (2008) found although a generalized trust of the larger population in one's new country may not lead to a significant sense of belonging in that country, a particularized trust -- a trust of one's neighbours or own group can do so. However, when these building blocks, such as feeling connected or feeling that one's language or culture is valued are not fostered (i.e. if we fail to/can't/struggle to connect and/or feel excluded), relational health, respect for the broader community (Croucher, 2009) and personal functioning may suffer (Reitmanova \& Gustafson, 2009).

Typically, OS is structured according to seven simple parameters: focus on intentional art-making, no judgmental commentary (positive or negative), non-evaluative in nature, no forced participation, witnessing, sharing, and participatory involvement of facilitators (Eleniak et al., 2016). The purpose of the learning space is to engage in art-making as a communitybased, social building activity. To avoid the inhibitions often experienced with art-making and arts-based process, no art-judging commentary, positive or negative, takes place between participants. Art projects are intentionally considered for non-complex techniques while still producing satisfying outcomes, and facilitator comments are descriptive rather than evaluative in 
nature. This way, exchanges among participants are social and familiarizing, which allows for comfortable engagement in the program. As a result, the work produced is in no way evaluated; as the focus is on the engagement in the art-making process. Moreover, participants who choose to attend the OS are not forced to engage in art-making; rather, their mere presence is seen as a form of participation, the process of art-making being emergent (Leavy, 2009; McNiff, 1998). The parameter of witnessing refers to participants' self-witnessing of their own process via journaling or quiet reflection, again non-judgmentally (no rejecting or appraising), where the artwork itself is a catalyst for writing. Sharing includes the sharing of finished or completed artworks via participant-planned events such as an invitation-only exhibit. Participants choose whether they wish to participate. Sharing work contributes to learning and to the cohesiveness of the group. Lastly, researchers and research assistants engage themselves in art-making alongside participants in a parallel process style of facilitation.

Use of visual art was appropriate in our context due to its universal accessibility as a nonverbal mode of expression (Moon, 2009). The process of an OS project allowed newcomer students to safely engage and explore how and where they experience belonging. Emerging imagery and themes informed the fostering of resiliency in times of great change in their lives.

\section{Research Team}

Our research team represented expertise in three main areas of research: Leah Lewis specializes in counselling psychology education with advanced knowledge of OS concepts; Heather McLeod specializes in art education; and Xuemei Li in second language education and newcomer integration. We also had the assistance of several research assistants who are knowledgeable in areas of working with newcomer youth and community-based arts practice.

Lewis is a registered creative arts therapist and psychotherapist, with graduate training in counselling psychology and arts-based research. She is a new scholar, and her scholarship is largely arts-based, focusing on areas of diversity, including newcomer experiences, illness and LGBTQ+ populations. The interest in arts-based research methods is shared by McLeod, who also pursues a critical research agenda. Her other research projects include an initiative to understand student experiential learning in an art museum setting.

Prior to this project, Li had been conducting research in newcomer students' language and academic support, as well as, newcomer career options and settlement support in NL for six years. She established collaborative work relationships with stakeholders in many areas. One of her projects investigated the high school refugee students' sense of belonging and integration (Li \& Grineva, 2016). She and her co-author pointed out existing problems with "school curriculum requirements, teacher preparedness, and peer interaction" (p. 67), and concluded that:

$[\mathrm{N}]$ ewcomer students had difficulties negotiating their cultural and religious identities. They were challenged in finding a "mediated space" (Li, 2015) in which they could live with conventions and concepts (such as dress codes and sexual orientations) not conforming to their home cultures and religions without losing their roots. (p. 68)

The authors thus called for educators to "find more effective ways to mediate the differences in a multicultural student population, particularly in a smaller centre with largely monocultural educational staff' (Li \& Grineva, 2016, p. 68) and encourage initiatives that 
"promote cultural awareness and intercultural communication" (p. 68). Our Open Studio project was one of the initiatives to promote cultural sharing and community building.

Our common interest in helping immigrant and refugee youth through community-based arts practice brought us together to carry out this classroom-based, hands-on project with youth at the province's largest and most culturally diverse high school, in St. John's. This site was ideal for OS because the school hosts comprehensive programing for new Canadians with diverse learning needs towards high school completion. The OS Project was a collaborative effort between the research team and the school's guidance counselor, as well as personnel working in the Literacy Enrichment and Academic Readiness for Newcomers (LEARN), Settlement Worker in Schools (SWIS), and English as a Second Language (ESL) programs. One research assistant, experienced in art, hosted OS programing, with assistance from student members of the youth leadership program, facilitated by the guidance program. A second research assistant participated and guided intercultural communication.

\section{Action Research}

This project adopted an Action Research (AR) approach. AR models of inquiry are inherently collaborative, where participants are included in some or all of the stages, including the process of collecting and reporting data (Hesse-Biber \& Leavy, 2011). AR frameworks are effective with arts-based research approaches as both rely on the emergence of themes via collaborative creative process (Leavy, 2009; McNiff, 1998). At the heart of AR practice is the knowledge that needs and solutions are both identified and fostered within the community itself. In this project, recruitment was facilitated by the counsellor and other teaching/supporting staff. These individuals and the participants became co-investigators of their own context and were therefore in a better position to help more immigrants and refugees understand their ways of being, sense of belonging, and aspirations for the future.

The focus of this project was to explore experiences of immigrant and refugee students as they find where and how they belong in the Newfoundland and Canadian contexts, through the weekly experiential arts-based program of OS. Using a model of participatory collaborative inquiry, community partnerships were made between the local University's Faculty of Education and the school's guidance program through partnering with an in-house counsellor. Our counselling contact acted as liaison for connections made between the research team and newcomer programing, namely English as a Second Language (ESL) programing for newcomer students. Recruitment primarily took place from existing school-based support as gatekeepers for informing and fielding questions from immigrant and refugee students. A weekly OS (aka popup OS) was offered, assisted by research assistants. Program content emphasized immigrant and refugee experiences and ideas of belonging via art-making and reflective journaling.

The number of participants in the OS was roughly 25 students, which varied somewhat from session to session. The students were from Brazil, Burundi, China, Congo, Eritrea, Ethiopia, Iraq, Jordan, Sierra Leon, Sudan, Syria, and Tanzania. The project ran weekly at HHM throughout the Winter and Spring of 2017 for 16 weeks. Data was sourced from an initial needs assessment, semi-structured pre and post interviews, a single focus group, and the visual art created. This triangulation of data increased the credibility of the data in that the ideas of the participants were expressed through verbal, interactional and visual modes.

Cultural and Pedagogical Inquiry, Summer 2018, 10(1), pp. 5-21

ISSN 1916-3460 C) 2018 University of Alberta

http://ejournals.library.ualberta.ca/index.php/cpi/index 
The OS sessions ran after school once a week for two and a half hours, loosely structured with a focus project each week, along with materials provided for independent work. Projects included group and individual mosaics, lantern making, still-life drawing, printmaking and papier maché bowls (shown). Other activities included knitting and crochet circles, which developed over time. Student participated in the making of artwork, designing of the art exhibit and mini-workshops teaching printmaking technique, and the decision-making in hosting the open house exhibit in house. Students wrote descriptions of the exhibited pieces, prepared and hung the artwork, as well as photographed selected data sources; art that depicted themes of belonging and inclusion.

A needs assessment was completed at the beginning of the process. The purpose of the needs assessment was to unearth emergent themes applicable to the focus group and the semistructured interviews. In the duration of the project, the research assistants paid attention to the participants' interaction and changing attitudes toward art-making, as well as their feelings of satisfaction and achievement about the art-making. The research team communicated promptly about the fieldwork at the school. Toward the end of the project, students' artwork was curated collaboratively with the participants and presented in an open house and art exhibition, entitled the Open Studio Open House. The event was held in the school, during which students hosted and instructed mini printmaking workshops to visiting students and outside invitees; family, friends and university faculty.

Focus groups are particularly useful in accessing deeper thoughts in a group and interpersonal setting. We organized and facilitated a focus group with the participants after the open-house exhibition at the end of the project. A slide show about the exhibition event was shown, and the participants were guided toward a conversation on connecting their experiences with their current life in Canada and NL through the OS program.

The interviews - conducted at pre and post points in the process -- explored intrapersonal experiences of belonging as they related to OS. Interview questions included exploring reasons for taking part in the program, types and styles of art created, media preferred, interpersonal experiences, and experiences of taking part in the open-house and art exhibit. Other questions engaged explicitly with experiences of belonging and inclusion, and how these might be informed by Open Studio, and making art together in a regular weekly gathering. Participants were able to choose the option of having their interviews video or audio recorded. The art work was photographed with artist consent (some images shown).

The research team met regularly to discuss the themes as they surfaced during data collection. In the initial stages of the data analysis, we invited the participants to help us make sense of their artwork. We performed a thematic analysis on the transcript data. This resulted in the three themes, to be presented below.

Due to the research design, we worked with the participants throughout the process, using an inclusive and collaborative approach. Researchers and facilitators engaged in art-making activities alongside the youth in an effort to diminish performance anxiety on the part of the students. From the beginning we considered an outcome that would take the form of an exhibition. Our intent was to work collaboratively with the young participants towards a public sharing of desired and selected art work. With some discussion, options of venue were explored, including the possibility of a community location away from school. The students voiced a desire

Cultural and Pedagogical Inquiry, Summer 2018, 10(1), pp. 5-21

ISSN 1916-3460 (C) 2018 University of Alberta

http://ejournals.library.ualberta.ca/index.php/cpi/index 
to host a pop-up OS in the school, and to invite other students and others from outside of school, to visit and learn about the group's experience. An art show was curated and hung by students and OS facilitators (research assistants), and special project tables were prepared for the purpose of hosting mini printmaking workshops for visiting students. A series of three half-hour workshops were led by OS youth during the open-house exhibit. This activity was observed as a "turning of tables", as it was the newcomer youth who hosted their Canadian peers, not the reverse. The newcomer participants felt a great sense of pride in being the hosts and inviting others into their familiar space. A collage of selected pieces is presented below.

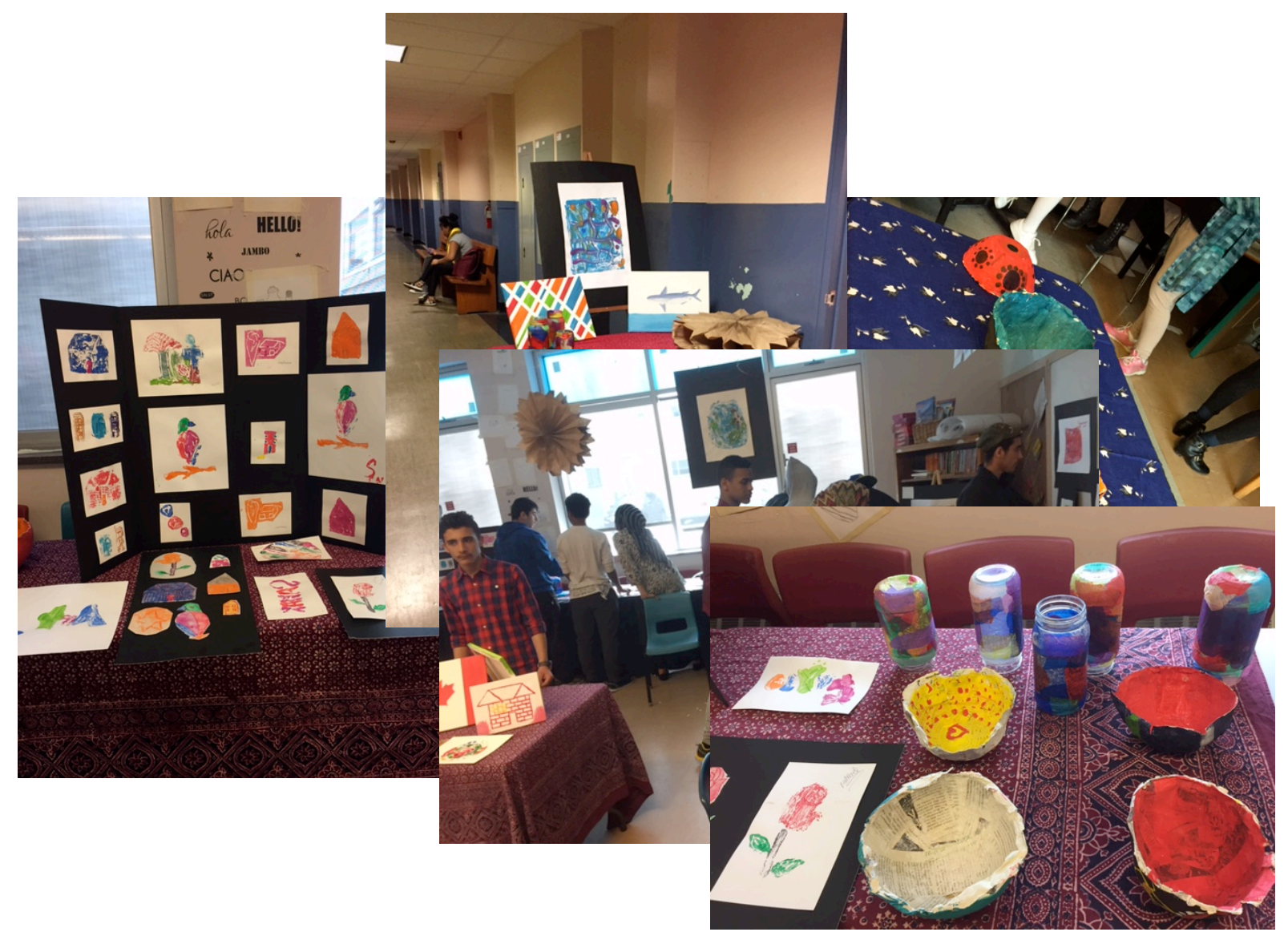

The OS schedule was revised a few weeks into our program when we noticed an abrupt decline in attendance. This absence was noted particularly among the boys. With some discussion, we soon learned that this change was due to the recent start of an after-school sports program. Because the students in question voiced a desire to attend both, we opted as a group to shift our OS day. The following week, attendance was fully restored. Because of this brief decline, we then added some weeks to the original 13-week program, making it a total of 16 weeks. 


\section{Open Studio as Public Home Space}

The OS Project sought to collaboratively explore the experiences of immigrant youth students' in St. John's. In particular, we were interested in facilitating a regular weekly space that was inviting, socially comfortable, and fostered an opportunity for students to connect and to create artwork together. The notion of the public home space, coined by Timm-Bottos and colleagues (2015), occurred to us as being applicable to how youth engaged with the OS space and process. Loose instruction provided project options for new attendees, while others opted to focus on individual pieces over time. The themes that surfaced from participant input speak to three prevailing areas of experience of newcomers to the urban region of NL. These are: OS as social space; OS as home; and English-learning in a non-evaluative setting.

\section{OS as Social Space}

Many of the student participants reported not having met one another prior to the OS group experience. Socializing outside of school time occurred infrequently due, in part, to living some distance from the school, as well as feeling disconnected from the community due to language and communication barriers. Because newcomer programing is centralized in this inner-city school, many newcomer youth are transported to and from school from multiple parts of the city every day. They attend class together, which involves intensive ESL learning and evaluation. Typically, however, they do not socialize with each other in and outside of school. The participants mentioned language uncertainty and unfamiliarity with the local area being part of the reasons. Many students took different levels of English classes and only encountered one another during the OS sessions. During the project, one teacher noticed that, "I see them (the ESL students) hanging out together. They're now spending time together (when they didn't before the OS program)."

\section{OS as Home} said:

Many youth reported feeling comfortable and at ease during OS sessions. One participant

“...It made me feel special...We don't... get those times, that people notice people from other countries... This is just art, but it grabs people from other countries... and they're all together... You don't feel like you're left out. It feels like home."

Because of their previous lack of opportunity to encounter even their own peers from ESL and LEARN programs, the OS proved an opportunity to begin to foster social relations in either English or their mother tongue. While facilitators spoke primarily English, language use between students was not monitored during OS sessions, as would be the case in more evaluative settings.

“...I feel just like I'm back in Ethiopia...connected with people, you know...even if you're from a different country.... like you both have similarities? Yeah, that's the biggest part. I like being around people that know... you know some people don't know much about me...but like, being with these people, you feel like at home...they understand my problems, and they can connect with me. They know how I feel. At least they have an idea.... think connecting with people is strong... and that's why I like Art Hive." 


\section{English-Learning in a Non-Evaluative Session}

English-learning was named as important and at times challenging. Many students reported English-learning occurred organically at the OS sessions. The facilitation was simply instructed in English. Since the OS attendees consisted of ESL learners at varying points in their ESL programing, more proficient students were able to assist those at earlier stages of English proficiency, with facilitated communication and casual translation. As this was not an academic program, students were not being evaluated on their English-learning; hence they reported experiencing less anxiety relating to language performance and evaluation. One student said, "if I have to work after school, I don't have fun....but in the art hive you have fun...,", and another stated,

"I feel at peace...you know with math you worry am I going to get this right, am I going to get this wrong, whatever...but art is just like...you put your ideas on paper...it gives me peace....yeah, I like doing it for myself...I just like, relax."

\section{Open Studio and Four Crucial ' $\mathrm{Cs}$ '}

Pulling from Adler's (1932) notion that one's sense of superiority increases with experiences that foster feelings of being valued and included in a community or group (Bettner \& Lew, 1990; Curlette \& Granville, 2014), we consider the role of group and creative gathering as a space in which the Crucial 'Cs' can be actively fostered. We note, from participant input and experiences, the possible ways that the OS framework might assist newcomer students' sense of belonging in school as a primary site from which long-term social learning is formed. For newcomer youth, these experiences are especially important, due to the sociocultural disconnect that is often experienced in new home countries, and particularly in Newfoundland and Labrador (Anderson, 2012).

We found the OS to be an effective space for social connection, with school itself being a community-situated location where social and peer engagement took place. For some of our newcomer youth, school was more than an academic institution; it was also a place for fostering social engagement, friendship and peer connecting. We drew connections between the four Crucial 'Cs' framework (Bettner \& Lew, 1990) and some of our observed outcomes, namely that each of the Crucial 'Cs' surfaced for the participants. Counting or being included in the OS group created cohesion. Competencies were developed in art-making (printmaking, still-life, mosaics, etc.), and leadership was fostered through students' facilitation roles during the mini printmaking workshops with Canadian peers. Courage evolved through experiencing and responding to a sense of risk to speak about and show one's work in a school-based art exhibition. Lastly, connections were fostered--friendships formed between ESL student peers who were not previously acquainted, something that had not been considered.

\section{Counting}

Adlerian psychology speaks to the experience that being valued as a contributing member of a group informs our development of a valued identity, or in Adlerian terms, a sense of superiority, rather than inferiority (Adler, 1932). Counting, or being valued in a group, tells us that we are noticed, that what we bring of ourselves is important, and that our absence will not be overlooked. Our newcomer youth spoke quite succinctly to this experience. One participant 
described this by saying, "We actually talk, instead of just walking past each other at school. Know what I mean?" That is, by facilitating the space in which youth could socially approach one another, the OS group provided an experience of being noticed by others.

\section{Connecting}

Many counselling models posit the role that interpersonal contexts play in overall wellbeing. From the Crucial 'Cs' framework (Bettner \& Lew, 1990), we understand the importance of interpersonal health as occurring through the act of connecting with others. Lack of ability to connect, to achieve intimacy in relationship and friendship, often runs in parallel with social isolation and feelings of exclusion and alienation. The experience of connecting with others further strengthens one's experience of belonging and of possessing significance (Bettner \& Lew, 1990). Many of our participants spoke about meeting peers for the first time during OS sessions, because previous opportunities for fostering friendships were difficult in other academic contexts where the focus was on learning. One participant spoke to this by saying, "I met new people--the people from basic English, basic ESL--we don't take class together, so I didn't know them..." The experience of meeting people they hadn't previously known was positive, adding to a sense of social cohesion. The participants also noted the particular connection they felt within the group: "Whether it's a happy moment, whether it's not... these people (OS peers) can understand you...without even explaining."

\section{Competent and Capable}

Bettner and Lew (1990) help us understand the importance of the experience of being capable as a feature of competency formation. The experience of being capable, regardless of the skill, reinforces the Adlerian state of superiority, and moves away from inferiority. The newcomer youth taking part in our OS attended groups to make art. The sessions were comprised of loose instruction regarding the mechanics of a given art project, for example printmaking, though students also worked on independent projects. Art-making as experience was noted by many as a newly acquired skill. "I never took art before... Right now, I know that I can do things..." is a comment shared by one of our participants that speaks to the experience of learning new competencies in art-making and in exhibiting self-made work.

\section{Courage}

The courage to engage in interpersonal interaction is a consequence of the previous Crucial 'Cs' (Bettner \& Lew, 1990). With an Adlerian lens, we understand interpersonally courageous acts as being indicative of a sense of inclusion (Eleniak et al., 2016). The ability to engage in developmentally enhancing forms of risk, such as speaking in front of a group or displaying a self-made art piece, cultivates feelings of confidence and social security. Courage among the participants was observed largely by teachers rather than the youth themselves. Selected students took on leadership roles during the open house exhibition event, whereby they introduced and toured our OS, explained its purpose, and facilitated a series of mini-printmaking workshops. While the participants themselves didn't name courage as part of their experience, input from teachers after the program ended noted that selected students who engaged in pseudoleadership roles had not done so previously. One teacher said, "Speaking to a roomful [at the open house exhibit], is not something that they have done... It was a great idea to do it in 'their space'."

Cultural and Pedagogical Inquiry, Summer 2018, 10(1), pp. 5-21

ISSN 1916-3460 (C) 2018 University of Alberta

http://ejournals.library.ualberta.ca/index.php/cpi/index 


\section{Thoughts on Gender}

The OS program remained relatively gender balanced in that both males and females attended all sessions. Attendance varied from the beginning to the end of the process, most notably with some change in attendance by participants from certain countries of origin. While the reason for this is unclear, speculation from school collaborators named gender mixing for groups such as this as being unfamiliar for some, while others' experiences of multiple cultures in one setting is still quite new. This is in keeping with certain cultural frameworks, including some Muslim youths' value systems, which are family system-informed (Hodge, 2002).

Therefore, consideration of culturally sensitive practice is important to our on-going research. It is particularly relevant to arts-based practices that take into consideration how cultural images are explored through art-making that may be sensitive to some participants; for example the representing of deity likenesses may not be culturally appropriate for many Muslims (Elias, 2012; Malchiodi, 2012).

\section{Final Thoughts}

In this project we explored an OS learning environment, drawing on the visual arts to promote personal reflection while demonstrating knowledge through action. Our conceptual framework integrated different and creative methods to engage our diverse learners/participants. Through this action research, as researchers, we have gained invaluable experience and knowledge. The on-site dynamics were an eye-opener for us in that despite the difficulties in their lives, the participants were hopeful and eager to integrate themselves into the new environment. The research team was touched by their desire for a non-judgmental space and their growing sense of belonging.

Current educational research on newcomer integration issues in NL has explored traditional ways of academic and social support, such as setting up language and academic bridging programs, providing for sports and extracurricular activities, and promoting peer interaction (Doyle, Li, \& Grineva, 2016; Li \& Grineva, 2016; Li, Doyle, Lymburner, \& Ghadi, 2016; Li \& Que, 2016;). Our OS project was a creative addition to the things we can do to foster the growth and well-being of immigrant and refugee youth in this province. It was a small project involving only immigrant and refugee youth in one school for 16 weeks; therefore, we do not intend to generalize the findings.

Our team will be expanding on this work with our upcoming Digital Stories Project, during which we will work with newcomer youth to teach digital story-making using devices such as their own smart phones and tablets. A public engagement initiative, students will develop digital stories inspired by their lived experiences of being newcomers to Newfoundland and Labrador, including the use of simple video editing software. Additionally, we foresee the benefits of larger cross-regional projects involving the OS approach with other groups of immigrants for the purpose of welcome and integration; including the development of a community-situated studio that will encourage newcomer and locals to engage in art-making together in a community studio setting. The emerging themes from our project can serve as a starting point. The form of 'pop-up' OS programing and a centrally-located community-based site are important options to consider. It is more desirable to pair an OS site with centres where English language classes are offered. A child-friendly, community-based environment will allow parents and grandparents to participate. In addition, multiple art-making techniques and media

Cultural and Pedagogical Inquiry, Summer 2018, 10(1), pp. 5-21

ISSN 1916-3460 (C) 2018 University of Alberta http://ejournals.library.ualberta.ca/index.php/cpi/index 
can be integrated, including clay, textiles (sewing, knitting etc.) and, painting and drawing. Furthermore, culturally-informed art-making should also be encouraged as a means of exchange of ideas and expertise, and a means of empowerment for the participants.

\section{Author's Note:}

This research was supported by a sub-grant from the Social Sciences and Humanities Research Council's (SSHRC) Pathways to Prosperity (P2P) Partnership Grant, and a Research and Development Grant from Memorial University’s Faculty of Education. 


\section{References}

Adler, A. (1932). What life should mean to you. London: Allen \& Unwin, Ltd.

Anderson, W. J. (2012). Immigration in rural Newfoundland: Individual and community change. Unpublished doctoral dissertation. University of New Mexico: http://digitalrepository.unm.edu/cgi/viewcontent.cgi?article=1029\&context=cj_etds

Association for new Canadians (2013). 2012-2013 Annual report. http://www.ancnl.ca/userfiles/files/ANC's\%20Annual\%20Report\%20$\% 202012 \% \mathrm{E} 2 \% 80 \% 932013 . \mathrm{pdf}$

Association for New Canadians (ANC) (2016). 2015-2016 Annual report. http://www.ancnl.ca/userfiles/files/ANC's\%20Annual\%20Report\%20\%202015\%E2\%80\%932016.pdf

Baker, J. (2013). Just kids? Peer racism in a predominantly white city. Refuge: Canada's Journal on Refugees, 29(1), 75-85.

Baker, J., Price, J., \& Walsh, K. (2015). Unwelcoming communities: Youth observations of racism in St. John's. Journal of Youth Studies, 19(1), 103-116. doi:10.1080/13676261.2015.1052048

Berthold, S. M. (2000). War traumas and community violence: Psychological, behavioral, and academic outcomes among Khmer refugee adolescents. Journal of Multicultural Social Work, 8, 15-46. https://doi.org/10.1300/J285v08n01_02

Bettner, B. L. \& Lew, A. (1990). Raising kids who can. Newton, MA: Connexions Press.

Block, D., Harris, T., \& Laing, S. (2005). OS process as a model of social action: A program for at-risk youth. Art Therapy, 22(1), 32-38. doi:10.1080/07421656.2005.10129459

Burnaby, B. (2010). The devil is in the details: Access for newcomer learners to ESL and ABE programs in St. John's (Condensed Edition). St. John's, NL: The Coalition on Richer Diversity (CORD) and the Refugee and Immigrant Advisory Council (RIAC).

Croucher, S. M. (2009). How limiting linguistic freedoms influences the cultural adaptation process: An analysis of the French Muslim population, Communication Quarterly, 57(3), 302-318.

Curlette, W. L. \& Granville, H. G. (2014). The four crucial Cs in critical friend groups, The Journal of Individual Psychology, 70(1), 22-30.

Doyle, A., Li, X., \& Grineva, M. (2016). Issues in newcomer education in smaller centers: Toward understanding educators' perspectives. The International Journal of Learner Diversity and Identities, 23(4), 1-17. http://ijldi.cgpublisher.com/product/pub.261/prod.109

Eleniak, D., Canning, S., Demill, K., \& Samra, R. (2016). Open art therapy studios on campus: A case study. Paper presented at 14th Annual International Conference on Education, Honolulu, Hawaii.

Cultural and Pedagogical Inquiry, Summer 2018, 10(1), pp. 5-21

ISSN 1916-3460 (C) 2018 University of Alberta

http://ejournals.library.ualberta.ca/index.php/cpi/index 
Elias, J. J. (2012). Aisha's cushion: Religious art, perception, and practice in Islam. Cambridge, UK: Harvard University Press.

Grant, T. (2016). 320,000 newcomers came to Canada in past year, highest number since 1971. The Globe and Mail, Wednesday, Sept. 28, 2016. https://www.theglobeandmail.com/news/national/canada-welcomed-320000-immigrantsin-past-year-highest-number-since-1971/article32102991/

Heron, J. \& Reason, P. (1997). A participatory inquiry paradigm. Qualitative Inquiry, 3(3), 274294.

Hesse-Biber, S. N. \& Leavy, P. (2011). The practice of qualitative research (2nd Ed.). Thousand Oaks, CA: Sage.

Hodge, D. (2002). Working with Muslim youth: Understanding the values and beliefs of Islamic discourse, Children and Schools, 24(1), 6-20. https://doi.org/10.1093/cs/24.1.6

Leavy, P. (2009). Method meets art: Arts-based research practice. New York, NY: Guilford.

Lepawsky, J., Phan, C., \& Greenwood, R. (2010). Metropolis on the margins: Talent attraction and retention in St. John's city-region. Canadian Geographer, 54(3), 324-346.

Li, X. (2015). International students in China: Cross-cultural interaction, integration, and identity construction. Journal of Language, Identity and Education, 14(4), 237-254. https://doi.org/10.1080/15348458.2015.1070573

Li, X. \& Grineva, M. (2016). Academic and social adjustment of newcomer youth at a Canadian high school. TESL Canada Journal, 34(1), 51-71.

http://www.teslcanadajournal.ca/tesl/index.php/tesl/article/view/1255

Li, X., Doyle, A., Lymburner, M., \& Ghadi, N. Y. (2016). Parental support of newcomer children's education in a smaller center. Comparative and International Education, 45(3), 1-15. http://ir.lib.uwo.ca/cie-eci/vol45/iss3/6/

Li, X. \& Que, H. (2016). Integration and career challenges of newcomer youth in Newfoundland in Canada. FIRE: Forum for International Research in Education, 2(3), 44-61. http://dx.doi.org/10.18275/fire201602031082

Li, X., Que, H., \& Power, K. (2017, forthcoming). Welcome to “the Rock”: Service providers' views on newcomer youth integration in Newfoundland and Labrador. Journal of International Migration and Integration. 18(4), 1105-1122. https://link.springer.com/journal/volumesAndIssues/12134

Locke, W. \& Lynch, S. (2005). A survey of the attitudes of employers in Newfoundland and Labrador toward the recruitment and employment of new Canadians and international workers. St. John's, NL: The Harris Centre. http://www.mun.ca/harriscentre/reports/research/2006/immigartion_final_report.pdf 
Malchiodi, C. (2012). Art therapy in practice: Ethics, evidence, and cultural sensitivity. In C. Malchiodi (Ed.), Handbook of Art Therapy (pp. 42-51). NY: Guilford.

McNiff, S. (1998). Arts-based Research. London: Jessica Kingsley.

Moon, C. H. (2009). Studio art therapy: Cultivating the artist identity in the art therapist. London: Jessica Kingsley.

Newman, T., Curtis, K., \& Stephens, J. (2003). Do community-based arts projects result in social gains? A review of the literature. Community Development Journal, 38(4), 310-322.

Office of Immigration and Multiculturalism (OIM), Government of Newfoundland and Labrador (2014). Provincial nominee program fact sheet. http://www.nlpnp.ca/pdf/factsheet_2014.pdf

Pearce, W. J. (2008). Bridging, bonding, and trusting: The influence of social capital and trust on immigrants' sense of belonging to Canada. Working Paper Series. Halifax, NS: Atlantic Metropolis Centre. http://community.smu.ca/atlantic/documents/2009.01.06WP18Pearce.pdf

Reitmanova, S. \& Gustafson, D. L. (2008). “They can't understand it”: Maternity health and care needs of immigrant Muslim women in St. John's, Newfoundland. Maternal and Child Health Journal, 11(1), 101-111.

Reitz, J. G. (2005). Tapping immigrants' skills: New directions for Canadian immigration policy in the knowledge economy. IRPP Choices, 11(1), 1-18.

Sarma-Debnath, K. \& Castano, A. (2008). Responding to the educational challenges of newcomer students and families. St. John's, NL: Multicultural Women's Organization of Newfoundland and Labrador.

Statistics Canada (2006). Visible minority population by census metropolitan areas (2006 Census). (St. John's, Halifax, Saint John, Saguenay). http://www.statcan.gc.ca/tables-tableaux/sum-som/101/cst01/demo53a-eng.htm

Statistics Canada (2011). Immigration and ethnocultural diversity in Canada, 2011 Census. http://www12.statcan.gc.ca/nhs-enm/2011/as-sa/99-010-x/99-010-x2011001-eng.cfm

Statistics Canada (2012). Focus on geography series, 2011 Census. http://www12.statcan.gc.ca/census-recensement/2011/as-sa/fogs-spg/Facts-preng.cfm?Lang=Eng\&GK=PR\&GC=10

Statistics Canada (2013). Population by mother tongue, by census metropolitan area, excluding institutional residents (2011 Census). (St. John's, Halifax, Moncton, Saint John). http://www.statcan.gc.ca/tables-tableaux/sum-som/101/cst01/demo12a-eng.htm

Statistics Canada (2016a). Focus on geography series, 2011 Census: Census subdivision of St. John's, CY - Newfoundland and Labrador. https://www12.statcan.gc.ca/census-recensement/2011/as-sa/fogs-spg/Facts-csdeng.cfm?LANG $=$ Eng \&GK $=\mathrm{CSD} \& \mathrm{GC}=1001519$

Cultural and Pedagogical Inquiry, Summer 2018, 10(1), pp. 5-21

ISSN 1916-3460 C) 2018 University of Alberta

http://ejournals.library.ualberta.ca/index.php/cpi/index 
Statistics Canada (2016b). Census profile, 2016 Census: St. John's [Census metropolitan area], Newfoundland and Labrador and Newfoundland and Labrador [Province]. http://www12.statcan.gc.ca/census-recensement/2016/dp$\mathrm{pd} /$ prof/details/page.cfm?Lang $=\mathrm{E} \& \mathrm{Geo} 1=\mathrm{CMACA} \&$ Code $1=001 \& \mathrm{Geo} 2=\mathrm{PR} \& \mathrm{Code} 2=10$ $\&$ Data $=$ Count $\&$ SearchText $=$ St. $\% 20 J o h n \% 27$ s\&SearchType $=$ Begins $\&$ SearchPR $=01 \& B 1$ $=\mathrm{All} \& \mathrm{TABID}=1$

Statistics Canada (2016c). Components of population growth, by province and territory (Newfoundland and Labrador, Prince Edward Island, Nova Scotia, New Brunswick).

http://www.statcan.gc.ca/tables-tableaux/sum-som/101/cst01/demo33a-eng.htm

Stermac, L., Brazeau, P., \& Martin, K. (2008). Educational experiences and mental health among war-zone immigrants in Toronto. Education Research and Reviews, 3, 370-377.

Timm-Bottos, J. \& Reilly, R. C. (2014). Learning in third spaces: Community art studio as store front university classroom. American Journal of Community Psychology, 55 (Special Issue), 102-114. doi:10.1007/s10464-014-9688-5

Timm-Bottos, J. \& Reilly, R. C. (2015). Neighborhood art hives: Engaging communities in teaching and learning. In O. Delano-Oriaran, M. Parks, \& S. Fondrie (Eds.), Servicelearning and civic engagement: A sourcebook (pp. 179-184). Thousand Oaks, CA: Sage.

Yalom, I. \& Leszcz, M. (2005). The theory and practice of group psychotherapy $\left(5^{\text {th }} \mathrm{Ed}\right.$.). NY: Basic Books. 